\title{
Microtopography Recreation Benefits Ecosystem Restoration
}

\author{
Wei Wei, ${ }^{*}{ }^{\dagger}$ Liding Chen, ${ }^{\dagger}$ Lei Yang, ${ }^{\dagger}$ F. Fred Samadani, ${ }^{\ddagger}$ and Ge Sun ${ }^{\S}$ \\ ${ }^{\dagger}$ State Key Laboratory of Urban and Regional Ecology, Research Center for Eco-Environmental Sciences, \\ Chinese Academy of Sciences, Beijing 100085, China \\ ${ }^{\ddagger}$ Environmental and Water Resources Management Consultant, Rockville, Maryland 20850, United States \\ ${ }^{\S}$ Southern Research Station, USDA Forest Service, Raleigh, North Carolina 27606, United States
}

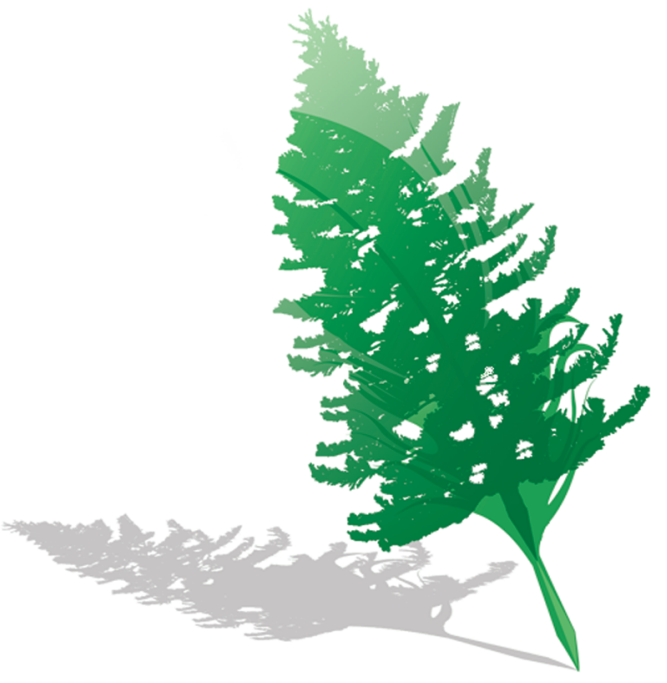

$\mathrm{W}$ ithin the context of global warming and accelerated human activities, the surrounding environments of many terrestrial ecosystems worldwide have become increasingly deteriorated, ${ }^{1}$ such that finding suitable methods and effective environmental technology to confront climate change and prevent land degradation is critical to the health and sustainability of the earth. In general, vegetation restoration projects, acknowledged as vital eco-engineering measures for various environmental benefits including carbon sequestration, soil conservation, and erosion control, are widely conducted in major fragile regions of the world. However, such projects have rarely been successful due to poor ecosystem productivity and quality, particularly in water-restricted and degraded ecosystems. ${ }^{2}$ It is also partly due to poor site conditions that do not enable naturally regenerated or planted seedlings to establish unless some external measures are applied. Consequently, to ameliorate site conditions and reduce sapling mortality, purposeful microtopography recreation is extensively used in many ecosystems during the initial stage of seedling plantation and vegetation re-establishment. Indeed, such countermeasures have been a significant benefit for ecosystem restoration, particularly in degraded habitats.

Man-made microtopography can create a mosaic of soil patches with substrates differing from the surroundings, and can markedly influence surface/subsurface hydrology, physicochemistry, and vegetation performance at different locations. ${ }^{3}$ Through prudent microtopography recreation, increased habitat heterogeneity can enhance soil moisture, nutrients, and elevation gradients remarkably, supporting a variety of physical niches and increasing ecosystem diversity. The diversity of ecosystem, however, is believed to be closely related to the ecosystem stability and sustainability. Furthermore, local degraded habitats can be greatly improved, which increases the survival ratio of plant community and accelerates vegetative regeneration. For example, soil moisture content in created hollows $(27-38 \%)$ is far higher than that in flats (14-25\%) and hummocks (3-13\%), inducing various biomass output and plant diversity in wetland ecosystems. ${ }^{3}$ In the desert pastures of New Mexico, a strong correlation between microtopography and the coverage of perennial grass $\left(R^{2}=91 \%\right)$ was found, whereas the loss of microtopography caused by livestock trampling hinders plant growth, exacerbating erosion process, and contributing to desertification. ${ }^{4}$ In the arid and semiarid regions of Chinese Loess Plateau (Figure 1), large-scale soil and water conservation methods,

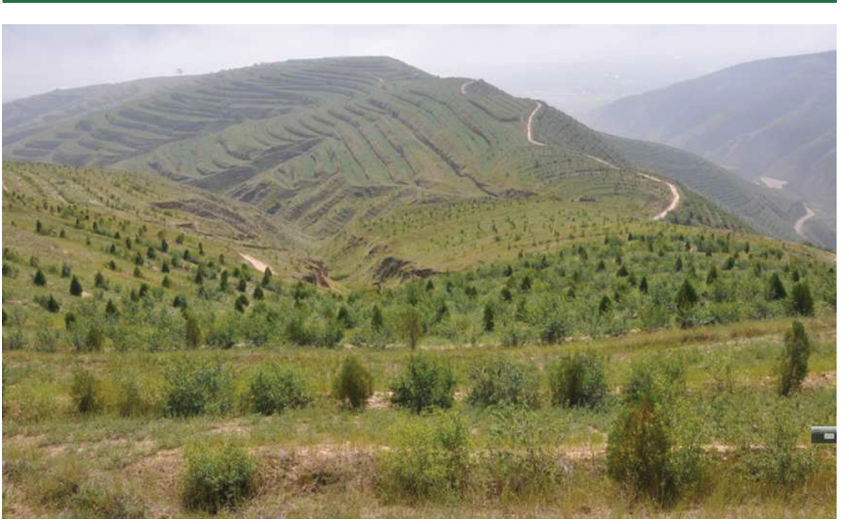

Figure 1. Diverse recreated microtopography features have greatly enhanced plant growth in Dingxi, a semiarid loess hilly area of China.

such as created fish-scale pits, horizontal ditch and zig terrace on slopes, and check-dam construction in channels, have greatly reduced downstream river flow and sediment load, helping to achieve the goal of vegetation recovery. ${ }^{5}$

Man-made microtopography benefits ecosystem restoration through a causal chain of processes. First, recreated microtopography alters rainfall redistribution and surface runoff path by adding topographic variation at fine scales. Consequently, ground roughness and infiltration rates at hillslopes are increased, the connectivity and velocity of overland flow are reduced, and the rate of soil erosion and nutrient export retard are followed by increased soil moisture, ultimately benefiting plant growth. ${ }^{2}$ Second, soil physiochemical features in situ can

Published: September 27, 2012 


\title{
Microtopography Recreation Benefits Ecosystem Restoration
}

\author{
Wei Wei, ${ }^{*}{ }^{\dagger}$ Liding Chen, ${ }^{\dagger}$ Lei Yang, ${ }^{\dagger}$ F. Fred Samadani, ${ }^{\ddagger}$ and Ge Sun ${ }^{\S}$ \\ ${ }^{\dagger}$ State Key Laboratory of Urban and Regional Ecology, Research Center for Eco-Environmental Sciences, \\ Chinese Academy of Sciences, Beijing 100085, China \\ ${ }^{\ddagger}$ Environmental and Water Resources Management Consultant, Rockville, Maryland 20850, United States \\ ${ }^{\S}$ Southern Research Station, USDA Forest Service, Raleigh, North Carolina 27606, United States
}

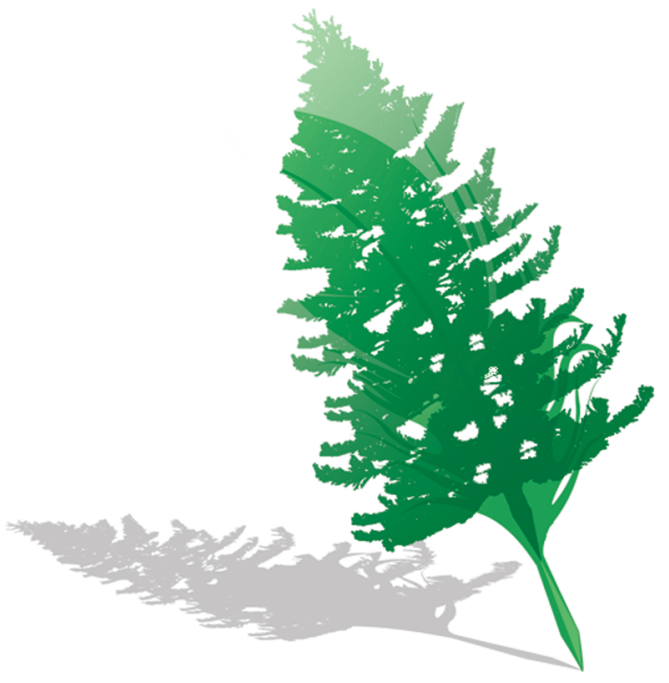

$\mathrm{W}$ ithin the context of global warming and accelerated human activities, the surrounding environments of many terrestrial ecosystems worldwide have become increasingly deteriorated, ${ }^{1}$ such that finding suitable methods and effective environmental technology to confront climate change and prevent land degradation is critical to the health and sustainability of the earth. In general, vegetation restoration projects, acknowledged as vital eco-engineering measures for various environmental benefits including carbon sequestration, soil conservation, and erosion control, are widely conducted in major fragile regions of the world. However, such projects have rarely been successful due to poor ecosystem productivity and quality, particularly in water-restricted and degraded ecosystems. ${ }^{2}$ It is also partly due to poor site conditions that do not enable naturally regenerated or planted seedlings to establish unless some external measures are applied. Consequently, to ameliorate site conditions and reduce sapling mortality, purposeful microtopography recreation is extensively used in many ecosystems during the initial stage of seedling plantation and vegetation re-establishment. Indeed, such countermeasures have been a significant benefit for ecosystem restoration, particularly in degraded habitats.

Man-made microtopography can create a mosaic of soil patches with substrates differing from the surroundings, and can markedly influence surface/subsurface hydrology, physicochemistry, and vegetation performance at different locations. ${ }^{3}$ Through prudent microtopography recreation, increased habitat heterogeneity can enhance soil moisture, nutrients, and elevation gradients remarkably, supporting a variety of physical niches and increasing ecosystem diversity. The diversity of ecosystem, however, is believed to be closely related to the ecosystem stability and sustainability. Furthermore, local degraded habitats can be greatly improved, which increases the survival ratio of plant community and accelerates vegetative regeneration. For example, soil moisture content in created hollows $(27-38 \%)$ is far higher than that in flats (14-25\%) and hummocks (3-13\%), inducing various biomass output and plant diversity in wetland ecosystems. ${ }^{3}$ In the desert pastures of New Mexico, a strong correlation between microtopography and the coverage of perennial grass $\left(R^{2}=91 \%\right)$ was found, whereas the loss of microtopography caused by livestock trampling hinders plant growth, exacerbating erosion process, and contributing to desertification. ${ }^{4}$ In the arid and semiarid regions of Chinese Loess Plateau (Figure 1), large-scale soil and water conservation methods,

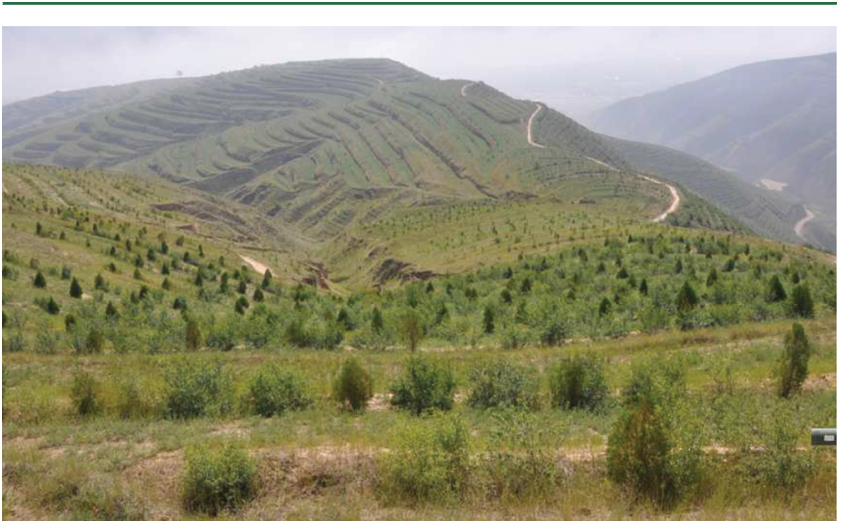

Figure 1. Diverse recreated microtopography features have greatly enhanced plant growth in Dingxi, a semiarid loess hilly area of China.

such as created fish-scale pits, horizontal ditch and zig terrace on slopes, and check-dam construction in channels, have greatly reduced downstream river flow and sediment load, helping to achieve the goal of vegetation recovery. ${ }^{5}$

Man-made microtopography benefits ecosystem restoration through a causal chain of processes. First, recreated microtopography alters rainfall redistribution and surface runoff path by adding topographic variation at fine scales. Consequently, ground roughness and infiltration rates at hillslopes are increased, the connectivity and velocity of overland flow are reduced, and the rate of soil erosion and nutrient export retard are followed by increased soil moisture, ultimately benefiting plant growth. ${ }^{2}$ Second, soil physiochemical features in situ can

Published: September 27, 2012 
be greatly enhanced through microtopography recreation. For example, compared with depressions, recreated hummocks and mounds have greater oxygen concentrations and higher nitrate $(P<0.0001)$ which facilitate the oxidation of ammonium $\left(\mathrm{NH}_{4}^{+}\right)$to nitrate $\left(\mathrm{NO}_{3}{ }^{-}\right)$via nitrification, and eventually affect soil and vegetation development. ${ }^{3}$ Through variations in inundation, microtopography affects redox conditions and redox sensitive nutrients. Moreover, soil salinity, organic matter, and alkalization have close correlations with microtopography dynamics. Third, manmade microtopography can create different microclimatic conditions, which are significant for seed germination and sapling upgrowth. Light interception, water thermal exchange, near-surface wind (velocity and direction), air temperature, and soil evaporation may differ across recreated suitable microlandforms, ${ }^{3,4}$ resulting in improved habitat and vegetation succession. Fourth, microtopography affects soil seed bank and potential plant distribution. The dispersal and germination of plant seeds, spores, and propagules are always constrained by the variation of microtopography and landscape position. In such situations, microtopography can act as seed refuge, determine potential vegetation pattern, and ultimately induce a higher heterogeneity of plant diversity and aboveground biomass. Last, microtopography may highly affect ecosystem functions and services. Some studies indicate that topographical heterogeneity within a few centimeters in surface relief can promote the richness and abundance of plant species. For example, white spruce (Picea glauca) communities at channels and concave slopes can provide higher green shading coverage and more carbon sequestration than those at ridges and convex slopes, confirming the crucial role of human-created microtopography in facilitating ecosystem restoration. ${ }^{4}$

In conclusion, although recreating microtopography benefits ecosystem restoration, problems and perplexities still remain, partly due to the complexity of microtopography and the absence of systematic observations. For example, although we acknowledge that scientific microtopography re-establishment may play key roles in improving habitat and vegetation rehabilitation, it remains unclear how much effect (the detailed and precise data) microtopography has or will have on local ecosystems, particularly when other natural or artificial factors are involved. Additionally, recreated microtopography may be diverse and complex in reality, also has temporal evolution features, and it is difficult to clarify what type of microtopography plays the most positive role in restoring degraded ecosystems. It is also unknown how different manmade microtopography can be spatially arranged to achieve the best environmental purpose in a certain location. In this connection, even though large-scale vegetation restoration accompanied by extensive microtopography recreation has been conducted in huge areas, the cumulative effects of reshaped microtopography on ecosystems have been largely neglected.

Some suggestions are highlighted here to address these problems. First, basic research and long-term monitoring should be conducted to detect the dynamic role between microlandform and ecosystems across scales. Furthermore, effects of different created microtopographies on ecosystem restoration should be compared and analyzed. Based on such tracking measurements, scientific microtopography selection, design, and pragmatic construction techniques should be developed, targeting any elusive possible ecological risks (e.g., induced by improper management) and achieving better environmental impacts. More attention, however, should be paid to the optimization of different microtopography distribution over time and space.
Only when such aspects are addressed, can ecosystem restoration receive a more promising and prosperous future, ultimately benefiting the Earth and humans.

\section{AUTHOR INFORMATION}

\section{Corresponding Author}

*Phone: +86(0)10-62849102; e-mail: weiwei@rcees.ac.cn.

\section{Notes}

The authors declare no competing financial interest.

\section{ACKNOWLEDGMENTS}

We thank Dr. Sindhu at Monash University and the editor for the constructive comments on the manuscript. This research was supported by the National Natural Science Foundation of China (40925003, 41230633).

\section{REFERENCES}

(1) Richard, A. K. Global warming is changing the world. Science 2007, 316, 188-190.

(2) Cao, S. X. Why large-scale afforestation efforts in China have failed to solve the desertification problem. Environ. Sci. Technol. 2008, 42 (6), 1826-1831.

(3) Bruland, G. L.; Richardson, C. J. Hydrologic, Edaphic, and Vegetative Responses to Microtopographic Reestablishment in a Restored Wetland. Restor. Ecol. 2005, 13 (3), 515-523.

(4) Wolf, K. L.; Ahn, C.; Noe, G. B. Microtopography enhances nitrogen cycling and removal in created mitigation wetlands. Ecol. Eng. 2011, 37, 1398-1406.

(5) Zhang, X. P.; Zhang, L.; Zhao, J.; Rustomji, P.; Hairsine, P. Responses of streamflow to changes in climate and land use/cover in the Loess Plateau, China. Water Resour. Res. 2008, 45 (7), 1-12. 